\title{
Analysis of the Current Application of Peripheral Intravenous Catheter and Indwelling Failure in the Department of Hepatobiliary Surgery
}

\author{
Xiaolan Wang, Mengying Qi, Yanhua Shi, Hualan Zhu, Weirong Li, Cuiqing Liu, Jin'ai He* \\ The First Affiliated Hospital of Jinan University, Guangzhou, China \\ Email address: \\ 1259130133@qq.com (Jin’ai He) \\ ${ }^{*}$ Corresponding author \\ To cite this article: \\ Xiaolan Wang, Mengying Qi, Yanhua Shi, Hualan Zhu, Weirong Li, Cuiqing Liu, Jin'ai He. Analysis of the Current Application of Peripheral \\ Intravenous Catheter and Indwelling Failure in the Department of Hepatobiliary Surgery. International Journal of Biomedical Science and \\ Engineering. Vol. 8, No. 4, 2020, pp. 44-50. doi: 10.11648/j.ijbse.20200804.11
}

Received: August 4, 2020; Accepted: August 31, 2020; Published: October 7, 2020

\begin{abstract}
Background: PIVC therapy is the most common hospital procedure. Its insertion and maintenance are easy to fail. Objective: To investigate the current application of peripheral venous catheter (PIVC) in the department of hepatobiliary surgery and the risk factors that lead to indwelling failure. Peripheral intravenous catheter therapy is one of the most common treatment procedures but has a relatively high failure rate during insertion and indwelling. Methods: A cross-sectional correlation study was adopted. Clinical data of patients receiving PIVC from March to June in 2019 in our hospital were collected. All patients were inserted with closed 24G IV catheters manufactured by BD Company, sealed with $50 \mathrm{U} / \mathrm{mL}$ heparin saline and secured by 3M Tegaderm Film-Transparent film dressing. Estuation caused by any reasons within 72 hours that failed to complete the treatment was considered to be indwelling failure. Univariate analysis was performed to analyze the effect of gender and age on the indwelling time, and logistic regression was used to analyze the related factors of indwelling needle-induced complications. The methods were consistent with the STROBE criteria (Supplementary File 1). Results: 445 patients were enrolled and clinical data from 395 patients were analyzed eventually, with a total of 773 PIVC cases. The indwelling time varied from $0.5 \mathrm{~h}$ to $329 \mathrm{~h}$ (median time $49.00 \pm 0.86 \mathrm{~h}$ ). Indwelling site: back of the hand (61\%), forearm (28\%), joint (6\%), upper arm (4\%) and finger (1\%). The success rate of one-time puncture was $92 \%$. PIVC indwelling failure rate was $46 \%$ which appeared to be higher in females and older people. Complications included exudation (72\%), phlebitis $(8 \%)$, blockage $(5 \%)$ and errhysis $(4 \%)$. There were no statistically significant differences in the incidence of complications in each indwelling period ( $\mathrm{P}>0.05)$. Logistic regression analysis showed that complications were independent risk factors for catheter indwelling failure (OR: 26.98, $\mathrm{P}<0.01$ ). Conclusions: PIVC mostly performed on the back of the hand and its indwelling time was associated with patients' gender and age in the department of hepatobiliary surgery. The occurrence of complications was an independent factor for PIVC failure.
\end{abstract}

Keywords: Peripheral Venous Catheter, Indwelling Failure, Department of Hepatobiliary Surgery

\section{Introduction}

Peripheral Intravenous Catheter (PIVC) was widely applied in Europe and the United States in the 1960s. Nearly 2 billion PIVC were consumed around the world each year with 200 million in the United States. It was reported that $79.1 \%-89.1 \%$ inpatients in China received IV infusion, and $99.3 \%$ patients had IV indwelling needles in first-class hospitals [1]. In Spain, approximately half of hospitalized patients received intravenous catheters among which $95 \%$ were PIVC [2-3].
Generally speaking, PIVC therapy is one of the most common hospital procedures. However, it has a relatively high failure rate during insertion and indwelling for many reasons.

According to the cross-sectional study on venous treatment conducted in our hospital in Mar 27, 67.96\% hospitalized patients had infusion among which $66 \%$ were PIVC. As a large number of patients required operations in the department of hepatobiliary surgery, the infusion rate reached up to $80.6 \%$ with about $2 / 3$ PIVC patients. However, situations like displacement, phlebitis, blockage, leakage, errhysis and 
infection during the procedure often resulted in early extubation which interrupted the treatment, increased catheter consumption and the risk of infection and damaging peripheral veins so that patients might suffer additional discomfort and pain, or even affected the intravenous medication time in severe cases. In this study, intravenous indwelling time less than $72 \mathrm{~h}$ or extuabtion within $72 \mathrm{~h}$ before finishing the treatment were considered to be indwelling failure [4]. Many studies had done to study indwelling failure. Some studies showed that more than $69 \%$ cases failed to indwell needles before completing the treatment [5-7]; Xu Chunmei et al [8] found that failure rate could reach $33.3 \%$; Rickard CM [9] suggested that the overall PIVC indwelling failure rate was between $35 \%$ and 50\%. The 2016 Infusion Therapy Standards of Practice published by the Infusion Nurses Society (INS) in the United States mentioned that the appropriate indwelling time for PIVC was around 72-96h but routine catheter replacement was not recommended [4, 9]. However, it was recommended to remove the catheters as soon as possible once there were symptoms (e.g phlebitis or other complications) occurred on the indwelling site or the treatment was finished $[10,11]$. To strengthen the investigation of the current PIVC application in the department of hepatobiliary surgery, this research was conducted to find out the risk factors of indwelling failure and the problems in clinical practice so as to eventually provide more theoretical support on clinical trial for hepatobiliary surgery nursing team and improve the quality of clinical nursing.

\section{Methods}

\subsection{Design}

Patients receiving PIVC infusion from March to June in 2019 in the the department of hepatobiliary surgery of the First Affiliated Hospital of Jinan University were enrolled in the study. Inclusion criteria incorporated patients aged $\geq 18$ years with oral consent from themselves or family members. Exclusion criteria were patients who inserted open indwelling needle during operation, or had short-term peripheral venous hyper-nutrition or unstable vital signs that might require first aid measures at any time, and patients with missing data or who dropped out were excluded as well. All patients were applied with closed $24 \mathrm{G}$ IV catheters manufactured by BD Company, sealed with $50 \mathrm{U} / \mathrm{mL}$ heparin saline and secured by 3M Tegaderm Film-Transparent film dressing (1264W). The indications of extubation were the occurrence of complications or completed treatment with no routine catheter replacement required. The criteria for complications were evaluated by visual phlebitis rating scale [9]. Exudation referred to the situations that the infusion fluid leaked from the vascular access into the surrounding tissue and the tissue became swollen, painful, and the infusion speed slowed down or venous access blocked. Catheter blockage referred to the inability to deliver medication or to pump blood from the catheter or both happened without fluid leakage. Accidental catheter detachment referred to be partial or complete catheter detachment from the vein, resulting in catheter function loss before reaching the indications of extubation. Catheter-related bloodstream infection referred to the occurrence of bacteremia or mycelial infection in patients along with clinical symptoms like chills and fever $\left(>38^{\circ} \mathrm{C}\right)$ during catheterization or within $48 \mathrm{~h}$ after extubation with the infections caused by external sources excluded. Errhysis usually occurred at the puncture site under dressing and impeded the observation of the puncture site [12].

\subsection{Data Collection and Tools}

According to the self-designed sheets based on literature and PIVC shift sheets [13], information like insertion time, extubation time, complications, puncture times, performers, extubation causes and intubation conditions on each shift were collected to find out the problems and deal with them in time. The STROBE checklist was used (Supplementary File 1).

\subsection{Data Analysis}

Data were analyzed by SPSS22.0, and the missing data were excluded. The continuous variables with normal distribution were expressed as mean, standard deviation and median, while the classified variables were expressed as frequency and percentage. Univariate analysis was applied to analyze the effect of gender and age on the indwelling time, and multivariate logistic regression was applied to analyze the potential risk factors of indwelling failure.

\section{Results}

445 patients' clinical data were collected initially but according to the research criteria, 50 patients with 120 PIVC cases were ruled out due to missing information about insertion or removal time, names or diagnosis results. 395 patients (220 (59\%) males and 175 (41\%) females, average age $57.5 \pm 16.1)$ with total 773 PIVC cases were included in the study eventually among which 353 (46\%) PIVC cases suffered from indwelling failure. The failure was mainly caused by complications like leakage, phlebitis, blockage, errhysis and detachment, as shown in table 1. In this study, the success rate of PIVC one-time puncture was $92 \%$ and 2.1 catheters were consumed by each patient on average.

Table 1. Summary of baseline characteristics of peripheral venous catheters.

\begin{tabular}{|c|c|c|c|c|c|}
\hline \multirow{2}{*}{ Variable } & \multicolumn{3}{|l|}{ PIVC indwelling failure } & \multirow{2}{*}{$R R(95 \% C I) / t$} & \multirow{2}{*}{$\boldsymbol{P}$} \\
\hline & Yes $(\mathrm{N}=353 ; 46 \%)$, No. $(\%)$ & No $(\mathrm{N}=420 ; 54 \%)$, No. $(\%)$ & Total $(\mathrm{N}=773)$, No.(\%) & & \\
\hline \multicolumn{6}{|l|}{ Gender $(\mathrm{N}=395)$} \\
\hline $\operatorname{Man}(N=220)$ & $189(42)$ & $263(58)$ & $452(58)$ & 1 & \\
\hline Woman $(\mathrm{N}=175)$ & $164(51)$ & $157(49)$ & $321(42)$ & $1.454(1.090-1.938)$ & $0.011^{*}$ \\
\hline
\end{tabular}




\begin{tabular}{|c|c|c|c|c|c|}
\hline \multirow{2}{*}{ Variable } & \multicolumn{3}{|l|}{ PIVC indwelling failure } & \multirow{2}{*}{$R R(95 \% C I) / t$} & \multirow{2}{*}{$P$} \\
\hline & Yes $(\mathrm{N}=353 ; 46 \%)$, No. $(\%)$ & No $(\mathrm{N}=420 ; 54 \%)$, No. $(\%)$ & Total (N=773), No.(\%) & & \\
\hline \multicolumn{6}{|c|}{ (2) } \\
\hline Mean (SD) & $59.4(16.0)$ & $56.0(16.0)$ & $57.5(16.1)$ & 2.968 & $0.003^{*}$ \\
\hline \multicolumn{6}{|l|}{ Puncture area } \\
\hline Finger & $5(56)$ & $4(44)$ & $9(1)$ & $1.346(0.352-5.149)$ & 0.924 \\
\hline The back of hand & $203(43)$ & $272(57)$ & $475(61)$ & $0.804(0.582-1.110)$ & 0.184 \\
\hline Wrist/elbow joint & $26(58)$ & $19(42)$ & $45(6)$ & $1.474(0.770-2.820)$ & 0.240 \\
\hline Forearm & $104(48)$ & $112(52)$ & $216(28)$ & 1 & - \\
\hline Upper arm & $15(54)$ & $13(46)$ & $28(4)$ & $1.243(0.564-2.736)$ & 0.589 \\
\hline \multicolumn{6}{|c|}{ Number of puncture attempts } \\
\hline 1 & $320(45)$ & $384(55)$ & $704(91)$ & 1 & \\
\hline$\geq 2$ & $33(48)$ & $36(52)$ & $69(9)$ & $0.909(0.554-1.492)$ & 0.706 \\
\hline Complication & & & & - & - \\
\hline Seepage & $251(73)$ & $94(27)$ & $345(45)$ & & \\
\hline Phlebitis & $29(76)$ & $9(24)$ & $38(5)$ & & \\
\hline Tube plugging & $22(59)$ & $15(41)$ & $37(5)$ & & \\
\hline Errhysis & $16(84)$ & $3(16)$ & $19(2)$ & & \\
\hline Detached & $6(75)$ & $2(25)$ & $8(1)$ & & \\
\hline \multicolumn{6}{|l|}{ Indwelling time (h) } \\
\hline Mean (SD) & $36.7(17.5)$ & $75.7(44.8)$ & $57.9(40.0)$ & - & - \\
\hline
\end{tabular}

*refers to $P<0.05$.

\subsection{Indwelling Time}

Results showed that the indwelling time of all PIVC cases varied from $0.5 \mathrm{~h}$ to $329 \mathrm{~h}$ with an average indwelling time of $57.89 \pm 1.44 \mathrm{~h}$ and a median indwelling time of $49.00 \pm 0.86 \mathrm{~h}$. There were 112 cases (14\%) within $24 \mathrm{~h}, 234$ cases $(30 \%)$ between 24 to $48 \mathrm{~h}, 204$ cases (26\%) between 48 to $72 \mathrm{~h}, 106$ cases $(14 \%)$ between 72 to $96 \mathrm{~h}$ and 117 cases $(15 \%)$ above 96 $\mathrm{h}$, as shown in table 2 .

\subsection{Selection of Puncture Site}

PIVC indwelling was mostly performed on the back of the hand (475 cases, 61\%) along with 216 cases $(28 \%)$ on the forearm, 45 cases $(6 \%)$ on the joint, 28 cases (4\%) on the upper arm, and 9 cases (1\%) on the fingers, as shown in table 2 .

Table 2. Summary of PIVC characteristics in different indwelling periods.

\begin{tabular}{|c|c|c|c|c|c|c|c|}
\hline \multirow[b]{2}{*}{ Variable } & \multicolumn{7}{|l|}{ Indwelling time (h) } \\
\hline & $\begin{array}{l}h<24(N=112,14 \%), \\
\text { No. } \%\end{array}$ & $\begin{array}{l}24 \leq \mathrm{h}<48(\mathrm{~N}=234,30 \%), \\
\text { No. } \%\end{array}$ & $\begin{array}{l}48 \leq h<72(N=204, \\
26 \%), \text { No. } \%\end{array}$ & $\begin{array}{l}72 \leq h<96(\mathrm{~N}=106, \\
14 \%), \text { No. } \%\end{array}$ & $\begin{array}{l}h \geq 96(N=117, \\
15 \%), \text { No.\% }\end{array}$ & $\chi^{2}$ & $P$ \\
\hline \multicolumn{8}{|l|}{ Puncture site } \\
\hline Finger & $0(0)$ & $6(67)$ & $0(0)$ & $3(33)$ & $0(0)$ & & \\
\hline The back of hand & $72(15)$ & $142(30)$ & $131(28)$ & $61(13)$ & $69(14)$ & & \\
\hline Wrist/elbow joint & $7(16)$ & $13(29)$ & $12(27)$ & $7(16)$ & $6(12)$ & & \\
\hline Forearm & $27(13)$ & $65(30)$ & $54(25)$ & $32(15)$ & $38(17)$ & & \\
\hline \multicolumn{8}{|l|}{ Complication } \\
\hline Seepage & 47 (14) & $111(32)$ & $93(26)$ & $47(14)$ & $47(14)$ & 2.088 & 0.720 \\
\hline Phlebitis & $10(26)$ & $12(32)$ & $7(18)$ & $6(16)$ & $3(8)$ & 6.353 & 0.174 \\
\hline Tube plugging & $5(13)$ & $9(24)$ & $8(22)$ & $4(11)$ & $11(30)$ & 6.521 & 0.163 \\
\hline Errhysis & $2(11)$ & $10(52)$ & $4(21)$ & $1(5)$ & $2(11)$ & 4.926 & 0.295 \\
\hline Detached & $4(50)$ & $2(25)$ & $0(0)$ & $2(25)$ & $0(0)$ & 11.218 & $0.024^{*}$ \\
\hline Not need & $31(11)$ & $78(27)$ & $86(29)$ & $46(16)$ & (17) & & \\
\hline
\end{tabular}

*refers to $P<0.05$.

\subsection{Complication Analysis}

In all PIVC removal causes, leakage occurred in 345 patients $(72 \%)$; 38 cases $(8 \%)$ phlebitis, mainly type I , II ; 37 cases $(5 \%)$ blockage; 19 cases $(4 \%)$ errhysis; 8 cases $(2 \%)$ detachment. No catheter-related bloodstream infections occurred; 26 cases $(8 \%)$ asked for early extubation due to discomfort or leaving; 2 cases (1\%) removed the catheters by themselves; 2 cases (1\%) had loose dressing; 1 case transferred to another department and 2 cases $(1 \%)$ removed with unknown reasons, as shown in table 2.
The results from the rank sum test of Kruskal Wallis $\mathrm{H}$ showed that leakage $\left(\chi^{2}=2.088, P=0.720\right)$, phlebitis $\left(\chi^{2}=6.353, P=0.174\right)$, blockage $\left(\chi^{2}=6.521, P=0.163\right)$, errhysis $\left(\chi^{2}=4.92, P=0.295\right)$ in different periods (within 24 hours, 24 to $48 \mathrm{~h}, 48$ to $72 \mathrm{~h}, 72$ to $96 \mathrm{~h}$, above $96 \mathrm{~h}$ ) had no statistically significant difference, while the incidence of catheter detachment in different periods $\left(\chi^{2}=11.218\right.$, $P=0.024)$ was statistically significant and had the highest incidence $(50 \%)$ within 24 hours.

\subsection{Analysis of Related Factors of Complications}

In the univariate analysis, PIVC indwelling failure rate in 
females were 1.5 time greater than that in males $(R R: 1.454,95 \%$ $C I$ : $1.090-1.938, P=0.011)$; Older patients had higher PIVC indwelling failure rate $(t=2.968, P=0.003)$. Logistic regression analysis showed that the occurrence of complications (OR: 26.98, 95\%CI: $17.48-41.64, P<0.01)$ was an independent factor of catheter indwelling failure, and the impacts of the five complications on indwelling failure was: errhysis $(84 \%)>$ phlebitis $\quad(76 \%)>$ detachment $\quad(75 \%)>$ exudation $(73 \%)>$ blockage $(59 \%)$, as shown in table 3 .

Table 3. Multivariate logistic regression analysis of PIVC indwelling failure.

\begin{tabular}{|c|c|c|c|c|}
\hline \multirow{2}{*}{ Variable } & \multicolumn{2}{|l|}{ PIVC retention failure } & \multirow{2}{*}{ OR $(95 \% \mathrm{CI})$} & \multirow{2}{*}{$P$} \\
\hline & Yes $(\mathrm{N}=353 ; 46 \%)$, No. $(\%)$ & No $(\mathrm{N}=420 ; 54 \%)$, No. $(\%)$ & & \\
\hline Gender $(\mathrm{N}=395)$ & & & - & 0.09 \\
\hline Man & $189(42)$ & $263(58)$ & & \\
\hline Woman & $164(51)$ & $157(49)$ & & \\
\hline Age & & & - & 0.26 \\
\hline Mean (SD) & $59.4(16.0)$ & $56.0(16.0)$ & & \\
\hline Puncture area & & & - & 0.43 \\
\hline Finger & $5(56)$ & $4(44)$ & & \\
\hline The back of hand & $203(43)$ & $272(57)$ & & \\
\hline Wrist/elbow joint & $26(58)$ & $19(42)$ & & \\
\hline Forearm & $104(48)$ & $112(52)$ & & \\
\hline Upper arm & $15(54)$ & $13(46)$ & & \\
\hline Number of puncture attempts & & & - & 0.45 \\
\hline 1 & $320(45)$ & $384(55)$ & & \\
\hline$\geq 2$ & $33(48)$ & $36(52)$ & & \\
\hline Complication & & & $26.98(17.48-41.64)$ & $<0.01^{* *}$ \\
\hline Yes & $324(72)$ & $123(28)$ & & \\
\hline No & $29(9)$ & $297(91)$ & & \\
\hline
\end{tabular}

** refers to $P<0.01$.

\section{Discussion}

This research was a single-center study of intravenous catheterization in the department of hepatobiliary surgery. The application of PIVC seemed to have less risk than that of CVC in adults with higher utilization rate and larger consumption. Therefore, it was necessary to investigate the failure rate of PIVC indwelling and the complications related to PIVC (e.g exudation, phlebitis, blockage, detachment, errhysis, infection) to ease the pain and anxiety of patients' re-catheterization and reduce the unnecessary consumption of indwelling needles. The success rate of PIVC one-time puncture in this research was $92 \%$ which was higher than that in the study of Sercan et al [14], 71\% success rate in old people. Other results [15] suggested that the success rate of the first puncture in 1201 cases was $73 \%$. This study was conducted mainly by nurses who were licensed and had received hospital training and scored more than 80 points in the assessment of intravenous indwelling needle puncture. In the United States, the United Kingdom, Australia and some other countries, venipuncture can only be operated by professionally certified nurses or doctors. However, although there are professionally certified nurses for venous treatment, venipuncture is allowed to be performed by any registered nurses in China. Despite the high success rate of one-time puncture, the failure rate of indwelling was $67.6 \%$ which was higher than that (45\%-50\%) found by Robert et al [16-20]. At present, there are still no relevant studies on indwelling failure rate in China.

\subsection{Selection of Puncture Site}

Most nurses and patients tend to choose the back of the hand as the puncture site, which maybe related to the fact that teachers began to train medical students from the distal intravenous injection and the students accustomed to practice on the back of the hand. The 2016 Infusion Therapy Standards of Practice pointed out that the forearm was the optimal position for indwelling needles, and the infusion practice standards in China suggested the same [21]. Studies showed that catheterization in forearm vein lasted longer and had a low incidence of adverse reactions with high satisfaction rate among patients and little impact on the limb activities so forearm vein was an ideal vessel for puncture [22-23]. Forearms provided a relatively large surface area to secure PIVC to help reduce pain, prolong indwelling time and reduce the incidence of accidental catheter displacement or blockage. Some studies also suggested that there was no significant correlation between the puncture site and the indwelling time of PIVC [24]. In this study, forearm venipuncture was performed in 216 cases $(28 \%)$, lower than the percentage (35.38\%) reported by Wei Tao et al [25], along with 475 cases $(61.4 \%)$ on the back of the hand, 45 cases $(5.8 \%)$ on joint, 28 cases $(3.6 \%)$ on upper arm, and 9 cases $(1.2 \%)$ on fingers, which was consistent with the results put forward by Evan Alexandrou et al that $1 / 3$ of PIVC was performed on the forearm, and mostly on the back of the hand, forearm vein or wrist [26]. However, these results were not consistent with the optimal operation sites recommended by the 2016 Infusion Therapy Standards of Practice. Therefore, training in site selection should be enhanced and should begin in school so that nursing students can recognize the importance of it as early as possible. Before intravenous therapy, nurses should complete the health education for patients and value the importance of site selection. Also, further investigation and 
corresponding measures should be put forward in view of the deficiencies in patients' health education.

\subsection{Selection of Catheter Type}

In order to meet the treatment needs, all patients in this study received treatment with $24 \mathrm{G}$ intravenous catheters, and those patients who needed larger size of catheters for treatment and rescue were excluded. Wallis et al [3] indicated that although the $22 \mathrm{G}$ or smaller indwelling needles can reduce the incidence of phlebitis, it increased the risk of accidental catheter displacement. The 2016 Infusion Therapy Standards of Practice published by Infusion Nurses Society (INS) recommended that the smallest type of indwelling catheter should be selected as long as it can meet the treatment needs. However, some clinical studies also questioned that $20 \mathrm{G}$ peripheral catheter was the optimal choice for adults [27]. Therefore, more studies are required to determine whether the catheter size should be as small as possible.

\subsection{Connection Between Age, Gender and Indwelling Time}

In univariate analysis, females had a higher risk of PIVC indwelling failure than males, and the failure rate appeared to be higher in older patients, which was consistent with the results put forward by Wallis et al [28-32] that females were more likely to suffer from PIVC indwelling complications than males, and the older the patients were, the shorter the indwelling time became. However, logistic regression analysis showed that the occurrence of complications was an independent risk factor only if the PIVC indwelling time was less than $72 \mathrm{~h}$.

\subsection{Connection Between Indwelling Time and Complications}

The results showed that the indwelling time varied from $0.5 \mathrm{~h}$ to $329 \mathrm{~h}$ with an average indwelling time of $57.89 \pm 1.44 \mathrm{~h}$ and a median indwelling time of $49.00 \pm 0.86 \mathrm{~h}$. There were 112 cases $(14 \%)$ within $24 \mathrm{~h}, 234$ cases $(30 \%)$ between 24 to $48 \mathrm{~h}$, and 204 cases $(26 \%)$ between 48 to $72 \mathrm{~h}$. Approximately $1 / 2$ PIVC could not last longer than $48 \mathrm{~h}$, which was consistent with the results that $50 \%$ of PIVC failed on the second day, reported by Kathy Kokotis et al [33]. Zhang L believed that the longer the indwelling time was, the higher the failure rate was [34]. Studies also showed that the incidence of complications (e.g. blockage, displacement, infiltration, exudation and phlebitis) related to PIVC reached up to $69 \%$ [35-37]. Logistic regression analysis showed that the occurrence of complications, such as exudation, phlebitis, blockage and errhysis was an independent risk factor for PIVC catheterization less than $72 \mathrm{~h}$. Among all the complications, incidence of leakage was as high as $44.63 \%$, which may be associated with the characteristics of the surgical patients. After general anesthesia, dullness, limb activity limitations and other side effects of patients may affect the infusion that the motionless limbs can prevent the leakage caused by the slip of catheters but it could also lead to poor blood circulation and venous reflux, resulting in local swelling and early PIVC extubation. In addition, general-anesthetized patients cannot drink water for a period of time before and after the operation so a large amount of fluid needed to be injected after the operation but the rehydration might aggravate the burden of infusion limbs, which could lead to local swelling on the puncture site. Among the five kinds of complications, exudation, phlebitis, blockage and errhysis in each period of the indwelling time had no statistical difference, indicating that they might occur in any period. Studies showed that phlebitis usually occurred relatively early (within 24h) [38]. No phlebitis above type II and catheter-related bloodstream infections were found in this study. Although the incidence of phlebitis in each time period was not statistically significant, statistics showed that $58 \%$ of phlebitis had occurred within 48 hours. Therefore, more attention should be paid to the early prevention of phlebitis during nursing work. Additionally, the incidence of catheter detachment was statistically significant in different indwelling periods with $75 \%$ occurred within $48 \mathrm{~h}$, which may be related to the large degree of limb movement on the indwelling side. Health education after indwelling was extremely important as well because $25 \%$ of catheter detachment occurred between $72 \mathrm{~h}$ and $96 \mathrm{~h}$, which may be caused by loose dressing.

The study was limited to patients in the department of hepatobiliary surgery and excluded the intraoperative intravenous catheterized patients, and therefore did not cover all catheterized inpatients. In addition, this study did not investigate the frequency of dressing changes and the criteria for dressing replacement during indwelling and also ignored the delayed extubation time and the patients' hand movements with intravenous indwelling.

\section{Conclusion}

This research on PIVC patients in the department of hepatobiliary surgery showed that the nurses had good venipuncture skills but still required more training and practice in the optimal indwelling position selection and the observation and prevention of complications. Administrators should choose appropriate evaluation tools, strengthen the assessment on nurses' PIVC practice, analyze the causes of complications, and carry out active prevention measures to have a timely detection and early treatment.

\section{Author Contributions}

Xiaolan Wang and Mengying Qi contributed equally to this work.

\section{Acknowledgements}

This study was supported by the Provincial science and technology plan of Guangdong province project: yuekegui caizi [2018] no. 145; Construction and effect evaluation of safe implementation mode of intravenous therapy in plateau area. 


\section{References}

[1] Sun H, Wang L, Guan X, et al. A survey of the status of infusion therapy in tertiary hospitals in China. Chinese Journal of Nursing, 2014, 49 (10): 1232-1237 [J]. (in Chinese with English abstract).

[2] Rickard CM, Marsh N, Webster J, et al. Securing all intravenous devices effectively in hospitalized patients-the SAVE trial: study protocol for a multicenter randomised controlled trial [J]. BMJ open, 2015, 5 (9): 1-6.

[3] Wallis MC, Mc Grail MR, Webster J, et al. Risk factors for PIV catheter failure: a multivariate analysis from a randomized controlled trial [J]. Infect Control Hosp Epidemiol, 2014, 35 (1): 63-68.

[4] Infusion Nurses Society. Infusion Nursing Standards of Practice [M]. Massachusetts: Infusion Nurses Society.

[5] New KA, Webster J, Marsh NM, Hewer B. Intravascular device use, management documentation and complications: a point prevalence survey [J]. Aust Health Rev. 2014, 38 (3): 345-349.

[6] Fernández-Ruiz M, Carretero A, Díaz D, et al. Hospital-wide survey of the adequacy in the number of vascular catheters and catheter lumens [J]. J Hospital Med. 2014, 9 (1): 35-41.

[7] Athanasio J D, Reichembach D M T, Adami V S, et al. Risk factors for complications in peripheral intravenous catheters in adults: secondary analysis of a randomized controlled trial [J]. Revista Latino-Americana de Enfermagem, 2016, 24: e2833.

[8] Xu CM. Study of the Effect of Cluster Nursing in prolonging safe retention time of peripheral venous indwelling needle [J]. CHINESE MANIPULATION \& REHABILITION MEDICINE, 2012, 3 (6): 119-120. (in Chinese with English abstract).

[9] Rickard CM, Webster J, Wallis MC. Routine versus clinically indicated replacement of peripheral intravenous catheters: a randomized controlled equivalence trial [J]. Lancet, 2012, 380 (9847): 1066-1074.

[10] Webster J, Clarke S, Paterson D, et al. Routine care of peripheral intra-venous catheters versus clinically indicated replacement: randomized controlled trial [J]. BMJ, 2008, 337 (7662): 157-160.

[11] O'Grady NP, Alexander M, Burns LA, et al. Guidelines for the prevention of intravascular catheter-related infections [J]. Clin Infect Dis, 2011, 52 (9): e162-e193.

[12] Simin D, Dragana Milutinović, Turkulov V, et al. Incidence, severity and risk factors of peripheral intravenous cannula-induced complications: An observational prospective study [J]. Journal of Clinical Nursing, 2019, 28 (9-10): 1585-1599.

[13] Jackson A. Bundle example for short peripheral IV catheter insertion and post insertion care [J]. IVTEAM Original. p. 1-6.

[14] Yalçınlı, Sercan, Akarca F K, Can, Özge, et al. Factors affecting the first attempt success rate of intravenous cannulation in older people [J]. Journal of Clinical Nursing, 2019, 28 (11-12): 2206-2213.

[15] Rippey JCR, Cooke M L, Trevenen M L, et al. Factors associated with peripheral intravenous cannulation first-time insertion success in the emergency department. A multicentre prospective cohort analysis of patient, clinician and product characteristics [J]. BMJ Open, 2019, 9 (4): e022278.

[16] Helm R E, Klausner J D, Klemperer J D, et al. Accepted but unacceptable: peripheral IV catheter failure [J]. Journal of Infusion Nursing, 2015, 38 (3): 189-203.

[17] Vick, Andrew M. Clinically-indicated replacement versus routine replacement of peripheral venous catheters. [J]. International Journal of Evidence-based Healthcare, 2013, 11 (4): 339-340.

[18] Webster J, Clarke S, Paterson D, et al. Routine care of peripheral intravenous catheters versus clinically indicated replacement: randomised controlled trial [J]. BMJ, 2008, 337: $1-6$.

[19] Bausone-Gazda D, Lefavier CA, Walters SA. A randomized controlled trial to compare the complications of 2 peripheral intravenous stabilization systems [J]. J Infus Nurs. 2010, 33 (6): $371-384$.

[20] Martínez JA, Piazuelo M, Almela M, et al. Evaluation of add-ondevices for the prevention of phlebitis and other complications associated with the use of peripheral catheters in hospitalized adults: a randomised controlled study [J]. J Hosp Infect, 2009, 73 (2): 135-142.

[21] National Health and Family Planning Commission of PRC. Nursing practice standards for intravenous therapy [J]. 2014. (in Chinese with English abstract).

[22] Cheng JJ, Liu YS, Xu Y, et al. Comparative study on the effects of venous indwelling needles on three different positions [J]. CHINA MEDICAL HERALD, 2011, 8 (23): 40-42. (in Chinese with English abstract).

[23] Zhao LQ, Tang SY, He Y. Indwelling position of peripheral venous indwelling needles in patients with cardiovascular diseases [J]. Journal of Clinical Research, 2013, 30 (2): 404-405. (in Chinese with English abstract).

[24] Tian CM, Jin LH. Study on the indwelling time of intravenous catheter system and relatively factors [J]. Chinese Journal of Practical Nursing, 2005, 21 (9): 7-9. (in Chinese with English abstract).

[25] Wei T, Tan Y, Shen YY, et al. Survey of the use of peripheral venous catheters in adult patients [J]. Journal of Nursing Science, 2018, 33 (17): 6-9. (in Chinese with English abstract).

[26] Alexandrou E, Ray-Barruel G, Carr P J, et al. Use of Short Peripheral Intravenous Catheters: Characteristics, Management, and Outcomes Worldwide [J]. Journal of Hospital Medicine, 2018, 13 (5). doi: 10.12788/jhm.3039.

[27] Tao YL, Zhou CL. Risk factors of venous indwelling needle-related phlebitis: a literature review [J]. Journal of Nursing Science, 2014, 29 (20): 89-90. (in Chinese with English abstract).

[28] Abolfotouh MA, Salam M, Bani-Mustafa A. et al. Prospective study of incidence and predictors of peripheral intravenous catheter-induced complications [J]. Ther Clin Risk Manag, 2014, 10: 993-1001.

[29] Dillon MF, Curran J, Martos R, et al. Factors that affect longevity of intravenous cannulas: a prospective study [J]. Q J Med, 2008, 101: 731-735. 
[30] Malyon L, Ullman A J, Phillips N, et al. Peripheral intravenous catheter duration and failure in paediatric acute care: A prospective cohort study [J]. Emergency Medicine Australasia, 2014, 26 (6): 602-8.

[31] Marsh N, Webster J, Larson E, et al. Observational Study of Peripheral Intravenous Catheter Outcomes in Adult Hospitalized Patients: A Multivariable Analysis of Peripheral Intravenous Catheter Failure [J]. J Hosp Med, 2017: E1-7 https://doi.org/10.12788/jhm.2867.

[32] Cicolini G, Bonghi AP, Di Labio L, et al. Position of peripheral venouscannulae and the incidence of thrombophlebitis: an observational study [J]. J Adv Nurs, 2009, 65: 1268-1273.

[33] Kathy Kokotis, Wang G, Li CY. Evaluation and suggestion on patients with early venous pathway [J]. Journal of Nursing Administration, 2013, 13 (5): 314-315. (in Chinese with English abstract).

[34] Zhang L, Cao S, Marsh N, et al. Infection risks associated with peripheral vascular catheters [J]. J Infect Prev, 2016, 17: 207-213.

[35] Marsh N, Larsen E, Genzel J, et al. A novel integrated dressing to secure peripheral intravenous catheters in an adult acute hospital: a pilot randomised controlled trial [J]. Trials, 2018, 19 (1): 596.

[36] Maralee Kanin, Guy Young. Incidence of thrombosis in children with tunneled central venous access devices versus peripherally inserted central catheters (PICCs) [J]. Thrombosis Research, 2013, 132 (5): 527-30.

[37] Murayama R, Uchida M, Oe M, et al. Removal of peripheral intravenous catheters due to catheter failures among adult patients [J]. J Infusion Nurse, 2017, 40: 224-231.

[38] Rickaed CM, McCann D, Munnings J, et al. Routine resite of peripheral intravenous devices every 3 days did not reduce complications compared with clinically indicated resite: a randomized controlled trail [J]. BMC Med, 2010, 8: 53. 